\title{
A Baroclinic Three Dimensional Numerical Model Applied to Coastal Lagoons
}

\author{
Lale Balas $^{1}$ and Erdal Özhan ${ }^{2}$ \\ ${ }^{1}$ Gazi University, Faculty of Engineering and Architecture, Civil Engineering Department, \\ 06570 Ankara, Turkey, \\ lalebal@gazi.edu.tr. \\ ${ }^{2}$ Middle East Technical University, Civil Engineering Department, Coastal Engineering \\ Laboratory, 06531 Ankara, Turkey \\ ozhan@metu.edu.tr
}

\begin{abstract}
An implicit baroclinic unsteady three-dimensional model (HIDROTAM3) which consists of hydrodynamic, transport and turbulence model components, has been implemented to two real coastal water bodies namely, Ölüdeniz Lagoon located at the Mediterranean coast and Bodrum Bay located at the Aegean Sea coast of Turkey. M2 tide is the dominant tidal constituent for the coastal areas. The flow patterns in the coastal areas are mainly driven by the wind force. Model predictions are highly encouraging and provide favorable results.
\end{abstract}

\section{Introduction}

Coastal water bodies are generally stratified which may cause significant vertical and lateral density gradients. In most of the real coastal water body applications, it is necessary to predict the vertical structure of the flow due to these density gradients. Similarly, the wind induced currents have a strong 3-D character, which require a comprehensive 3-D numerical model. A three dimensional numerical model has been developed to simulate the transport processes in coastal waters by the authors [1]. In coastal water bodies such as estuaries, lagoons or bays, the horizontal length scale is much larger than the vertical scale. The flow is predominantly horizontal and the vertical acceleration is hardly compared with the gravity acceleration. The tidal range of the Turkish Mediterranean Sea coast is small, the spring ranges being typically $20-30 \mathrm{~cm}$., hence the dominant forcing for circulation and water exchange is due to the wind action. In the literature, it is possible to find a large number of one, two and three dimensional numerical models which have been used for the estimation of circulation patterns and water quality in coastal water bodies [2], [3].

\section{Application to Ölüdeniz Lagoon}

With the developed three dimensional numerical model, the tidal circulation patterns are investigated in Ölüdeniz Lagoon by using an input tidal wave with an amplitude of $\mathrm{a}=0.15 \mathrm{~m}$. and a period of $\mathrm{T}=12$ hours $25 \mathrm{~min}$ [4]. Ölüdeniz Lagoon is located at the 
Mediterranean coast of Turkey (Figure 1). Turkish coastline along the western Mediterranean is increasingly being popular. Öludeniz Lagoon which is strategically located along the sailing route, is busy almost all over the year. The town of Fethiye located inland of the lagoon is one of the most developed coastal resorts along the Turkish coastline. In order to prevent the excessive pollution, it is forbidden to enter the lagoon waters by any motorboats. Simulation is started from the state of no motion at the low tide when the water level is minimum everywhere in the lagoon, and the tidal currents are zero. Then water level along the open sea boundary increases with respect to a sinusoidal wave. Flow velocities are computed at 6 levels along the water depth. The density of the water is assumed to be constant. The shoreline boundary is assumed to be fixed. The horizontal square mesh size is constant, $\Delta x=\Delta y=20 \mathrm{~m}$. To simulate the pollutant transport an inner mesh is fitted to the area as shown in Figure 2.

The propagation of the tidal wave is mainly affected by the geometric and topographic conditions. The mean water depth at the entrance channel is around 3.5 $\mathrm{m}$. and the width is around $60 \mathrm{~m}$. Due to this narrow and shallow entrance, tidal currents are damped out. Therefore the tidal velocities inside the lagoon are hardly compared with the velocities around the entrance channel. The period of the tidal wave, semi diurnal type, is so long that, the wave length is much larger than the length of the coastal water body considered. Therefore the associated displacement of the waters is essentially horizontal, resulting in nearly horizontal flows. The flow directions at all layers are nearly the same.

Using the estimated tidal current patterns, the transport of a pollutant is also simulated. For the simulation of the transport of pollutant discharged at the point shown on Figure 2, the coliform count is used as the tracer. The initial concentration is taken as $10^{6} \mathrm{bac} / \mathrm{ml}$ at the discharge point and is assumed to be $1 \mathrm{bac} / \mathrm{ml}$ in the rest of the lagoon waters. The discharge is assumed to take place steadily into the surface layer and to start at the same time as the tidal action. It is assumed that the value of $\mathrm{T}_{90}$ is 2 hours. Vertical eddy viscosity is calculated by the $\mathrm{k}-\varepsilon$ turbulence model. Since the horizontal motion has an intensity, the Smagorinsky algebraic sub-grid scale turbulence model is used to estimate the horizontal eddy viscosities. The distribution of pollutant concentrations at the surface (from inner to outer contour in $\mathrm{bac} / \mathrm{ml}$ is: 900000, 300000, 100000, 50000, 25000, 10000, 5000, 2500, 1000, 500, 250, 10) and at the bottom (from inner to outer contour in bac/ml is: 10000, 5000, 2500, 1000, 500, $250,10)$ layers are given hourly in Figure 3 . It is seen that the progress of pollutant is stabilized almost at 6 hours, and it covers the computational grid shown in the Fig. 2. The pollutant concentration level at the bottom layers is about 10 times less than the level at the surface layers.

\section{Application to Bodrum Bay}

Model has been applied to Bodrum Bay to simulate the circulation pattern and the transport of pollutant. Bodrum Bay is located at the Aegean Sea coast of Turkey (Figure 1) where the dominant forcing for the water exchange is due to the wind action. The town of Bodrum located inland of the Bay is one of the most developed coastal resorts along the Agean Sea coast of Turkey. In Bodrum Bay, there are two sea outfalls discharging directly into the Bay. The sea outfall at Kizılburun has a length of $1500 \mathrm{~m}$. 
and the one at İnceburun has a length of $900 \mathrm{~m}$. They discharge nearly at water depths of $40 \mathrm{~m}$.

The sea outfalls are shown in Figure 4 with a dotted line. The grid system used has a square mesh size of $350 \times 350 \mathrm{~m}$. Near the sea outfall a more refined mesh with a grid size of $50 \mathrm{~m} \times 50 \mathrm{~m}$. is fitted. The water depth is divided into 6 layers of equal thickness. In the simulations of pollutant transport the coliform count is used as the tracer. The rate of disappearance of pathogenic bacteria and viruses due to die-off approximately follows first order kinetics. The die of constant $k_{p}$, is computed in terms of $\mathrm{T}_{90}$, the time required for 90 percent of the initial bacteria to die, and equals $2.3 / \mathrm{T}_{90}$.

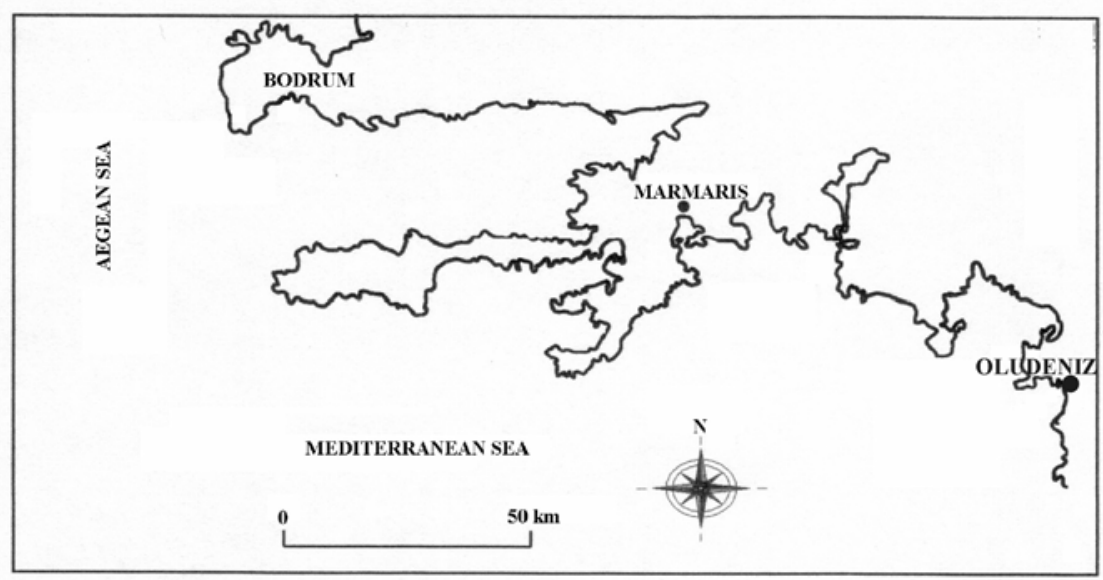

Fig. 1. Location of Bodrum Bay and Ölüdeniz Lagoon.

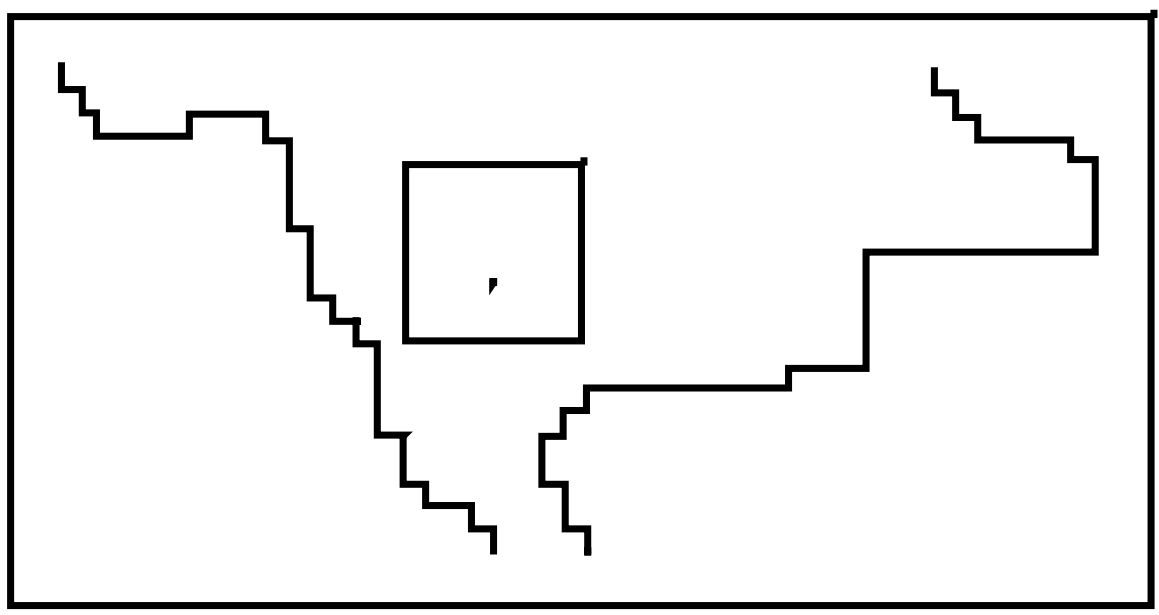

Fig. 2. Pollutant discharge location and the computational grid of Ölüdeniz Lagoon. 


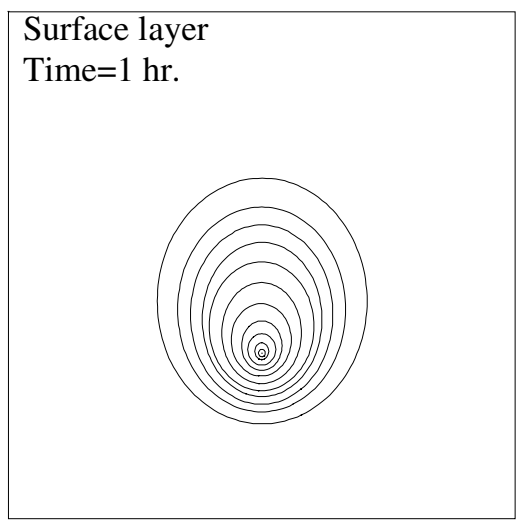

Surface layer

Time $=2$ hours

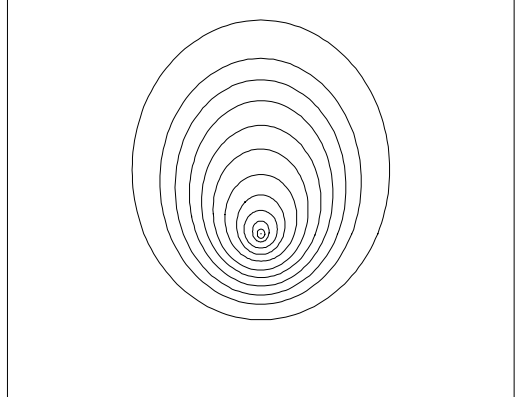

Surface layer

Time $=3$ hrs.

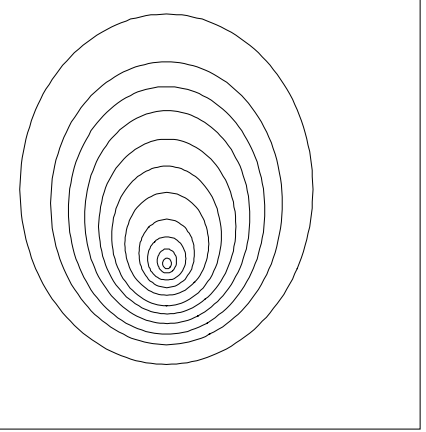

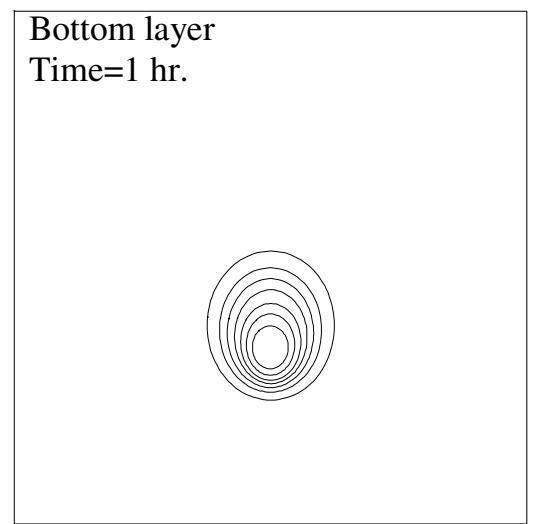

Bottom layer

Time $=2$ hrs.

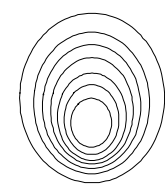

Bottom layer

Time $=3$ hrs.

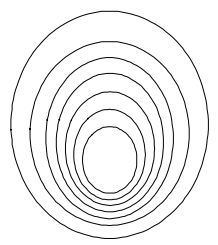

Fig. 3. Progress of concentration contours under tidal action. 


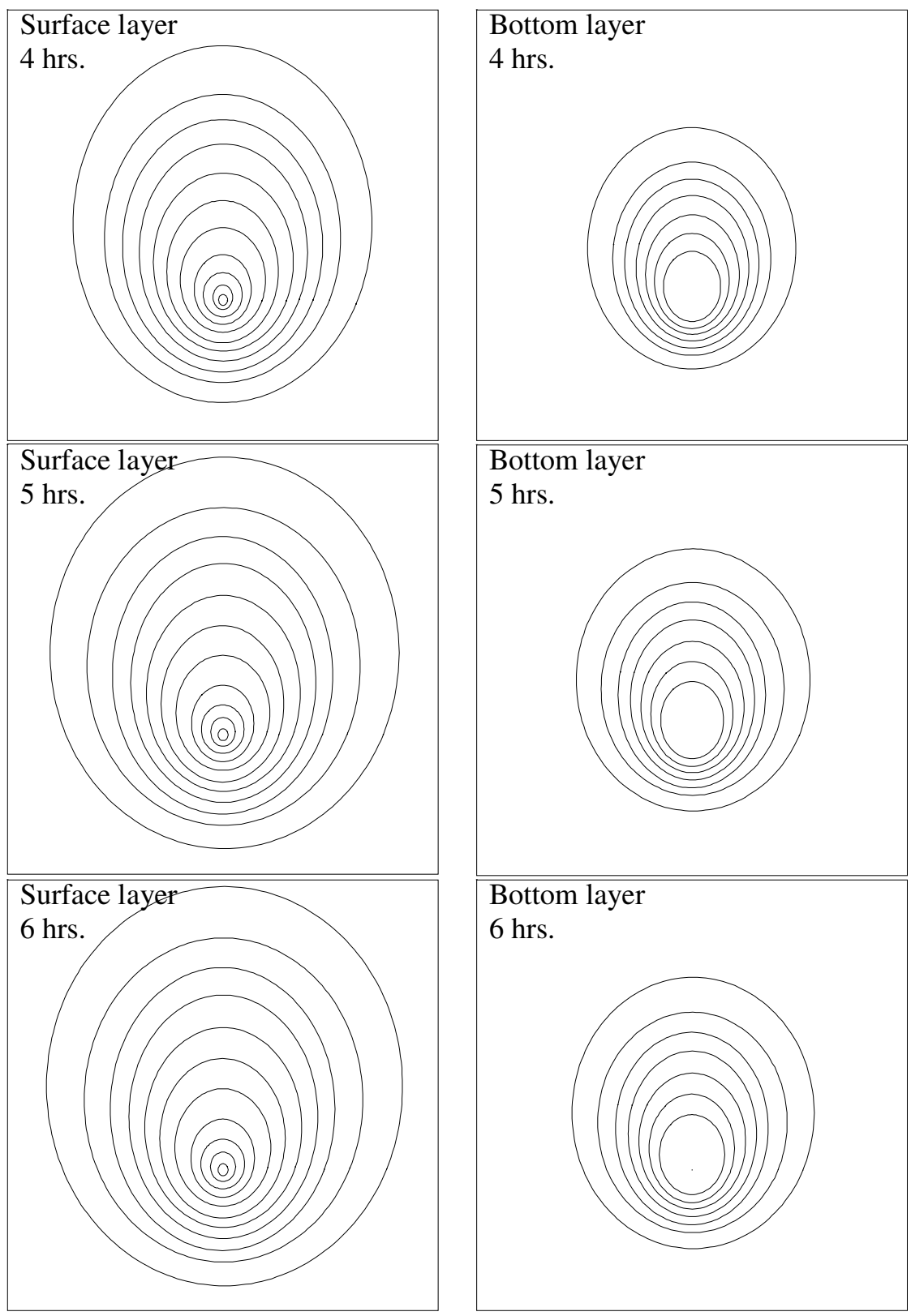

Fig. 4. (cont'd). Progress of concentration contours under tidal action.

For the coastal area wind shear is the dominant forcing that induce circulation. Wind characteristics are obtained from the measurements of the meteorological station in Bodrum for the period of 1990-2001. The wind analysis shows that the most critical wind 
direction for wind speeds greater than $5 \mathrm{~m} / \mathrm{s}$, is the SSW direction. In the model simulations, Bodrum Bay is subjected to a wind action with a speed of $8 \mathrm{~m} / \mathrm{s}$. blowing from SSW. Simulation is started from a state of rest that, there is no water motion and water surface is horizontal. The steady state is reached approximately 4 hours after from the start of the wind action. The water density is taken constant. Horizontal eddy viscosities are calculated by the sub-grid scale turbulence model and the vertical eddy viscosity is calculated by the $\mathrm{k}-\varepsilon$ turbulence model.

The steady state flow patterns near the surface and the bottom are sketched in Figure 4 and Figure 5 respectively. The transport of a pollutant is simulated using the coliform count as the tracer. The initial concentration is taken as $10^{6} \mathrm{bac} / \mathrm{ml}$ at the discharge point. The discharge is assumed to take place steadily. $\mathrm{T}_{90}$ value is measured as 1.5 hours. Distribution of pollutant concentrations at the surface and at the bottom layers are showen in Figure 4 and in Figure 5 respectively. The area which has pollutant concentrations over $10^{3} \mathrm{bac} / 100 \mathrm{ml}$ is a considerable area that includes the coastal band width of $200 \mathrm{~m}$.

Sea outfalls in Turkey must obey the regulations stated by the Turkish Water Pollution Control Regulations [5]. Some of the regulatory norms are summarized here; a)The initial dilution should not be less than 40 and preferably be more than 100; b)During the summer season, $\mathrm{T}_{90}$ value should be taken at least equal to 2 hours for the Mediterranean Sea and the Aegean Sea, and to 1.5 hours for the Black Sea; c) The total dilution should be sufficient to yield less than 1000 total coliform per $100 \mathrm{ml}$ for $90 \%$ of the time when sampled in preserved areas of human contact within $200 \mathrm{~m}$ from the shoreline; d) The minimum discharge depth should be $20 \mathrm{~m}$. If reaching this depth is impractical, then the length of the discharge pipe, excluding the diffusor section, should not be less than 1300 $\mathrm{m}$ for waste water flow rates larger than $200 \mathrm{~m}^{3} /$ day.

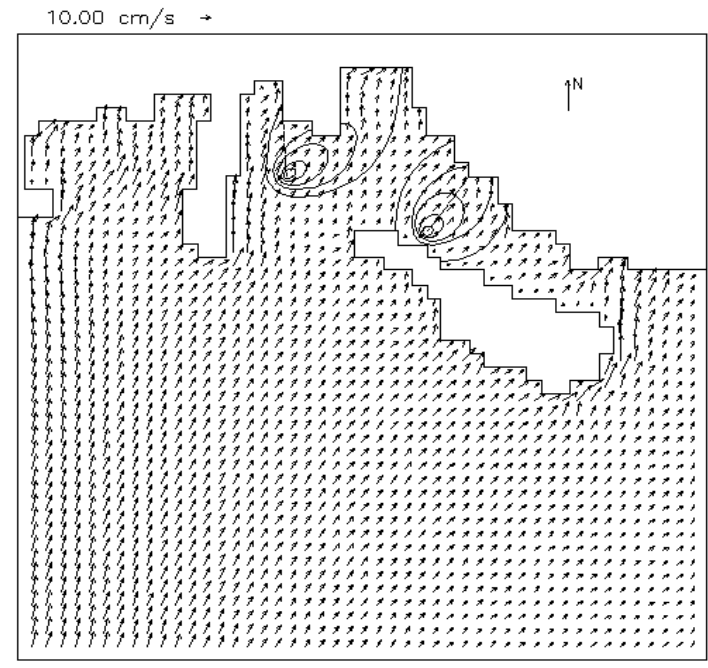

Fig. 5. Circulation pattern at the sea surface and pollutant contours (Pollutant contours from inner to outer: $500000 \mathrm{bac} / 100 \mathrm{ml}, 100000 \mathrm{bac} / 100 \mathrm{ml}, 25000 \mathrm{bac} / 100 \mathrm{ml}, 5000 \mathrm{bac} / 100 \mathrm{ml}, 1000$ $\mathrm{bac} / 100 \mathrm{ml})$ 


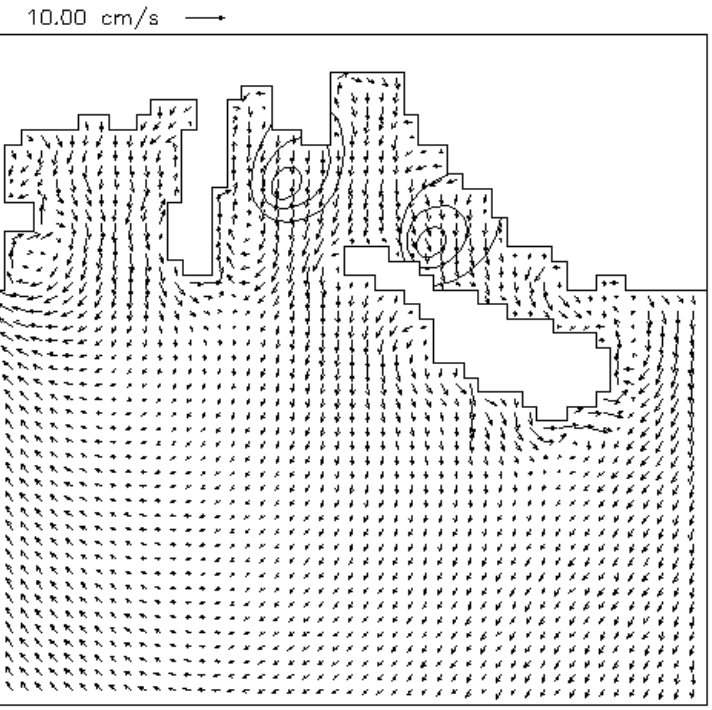

Fig. 6. Circulation pattern at the sea bottom and pollutant contours (Pollutant contours from inner to outer: $100000 \mathrm{bac} / 100 \mathrm{ml}, 5000 \mathrm{bac} / 100 \mathrm{ml}, 1000 \mathrm{bac} / 100 \mathrm{ml}$ ).

\section{Conclusions}

An implicit baroclinic 3-D numerical model developed to simulate the transport processes in coastal waters is presented. Model is applied to Ölüdeniz Lagoon to simulate the tidal circulation pattern and the dispersion of a pollutant discharged near the lagoon entrance. Model predictions are encouraging for Ölüdeniz Lagoon that is a type of chocked lagoon. Model predictions are also compared with the site measurements, which are in good agreement with each other [6]. Model has been applied to Bodrum Bay that there exist two sea outfalls discharging into the Bay. The model with a great success simulates wind induced circulation pattern and the pollutant diffusion. Presented 3-D model HIDROTAM3, can serve as a powerful design tool and can be implemented in Decision Support Systems.

\section{References}

1. Balas, L., Özhan E. : An Implicit Three Dimensional Numerical Model to Simulate Transport Processes in Coastal Water Bodies, International Journal for Numerical Methods in Fluids (SCI-Core), 34, (2000) 307-339.

2. Huang, W., Spaulding, M. : 3D model of estuarine circulation and water quality induced by surface discharges, Journal of Hydraulic Engineering, ASCE, 121, (1995) 300-311.

3. Roberts, P.J.W. : Modeling Mamala Bay outfall plumes, II: Far field”, Journal of Hydraulic Engineering, ASCE, 126(6), (1999) 574-583. 
4. Balas L., Özhan E. : Flushing of Ölüdeniz Lagoon, Proceedings of the Joint Conference MEDCOAST'99-EMECS'99, Antalya, Turkey, Vol.3, (1999) 1873-1884.

5. Balas, L. : Simulation of Pollutant Transport in Marmaris Bay", China Ocean Engineering, 15 (4), (2001) 565-578.

6. Balas L., Özhan E.: Applications of a 3-D Numerical Model to Circulations in Coastal Waters", Coastal Engineering Journal, CEJ, 43, No 2., (2001) 99-120. 